\title{
XAMANISMO E REDES DE RELAÇÕES INTERINDÍGENAS: AMAZÔNIA E NORDESTE BRASILEIRO
}

\author{
SHAMANISM AND INTER-INDIGENOUS \\ RELATIONSHIP NETWORKS: AMAZON \\ AND BRAZILIAN NORTHEAST
}

Ugo Maia Andrade

ugomaia@ufs.br

Programa de Pós-Graduação em Antropologia e Programa de Pós-Graduação em Arqueologia da Universidade Federal de Sergipe. Doutor em Antropologia/USP.

Orcid: https://orcid.org/0000-0002-0359-3214

\section{RESUMO}

Trata-se de produzir considerações a partir de dois contextos etnográficos distintos de relações de trocas interindígenas baseadas no xamanismo: o submédio São Francisco (divisa BA/PE) e o baixo Oiapoque e rio Uaçá (fronteira Brasil/Guiana Francesa). Caracterizadas por suas respectivas literaturas etnológicas como antigas zonas de contato entre índios e entre índios e não índios - experimentando densamente as presenças colonial e missionária - as regiões em pauta apresentam ainda hoje relevantes circuitos de trocas xamânicas que vão da complementaridade ritual à dissensão provocada por acusações de feitiçaria, modulando relações políticas intra e intercomunitárias. Essas permutas estão conectadas a outras de tipos matrimonial, comercial, etc., não configurando um domínio autônomo de relações intersociais. Contudo, dada a importância dos intercâmbios rituais nos registros das relações interindígenas em ambas regiões, faz-se necessário indagar e cotejar os princípios que os ordenam e suas transformações nas respectivas histórias regionais.

Palavras-chave: Xamanismo. Submédio São Francisco. Baixo Oiapoque e rio Uaçá.

\begin{abstract}
It is about producing considerations from two distinct ethnographic contexts of interindigenous relations based on shamanism: the sub-middle São Francisco River (BA-PE limits) and the lower Oiapoque River (Brazil-French Guiana border). Characterized by their respective ethnological literatures as ancient zones of contact between Indians and between Indians and non-Indians, densely experiencing the colonial and missionary presences - the regions on the agenda still present relevant circuits of shamanic exchanges that range from ritual complementarity to dissension caused by sorcery accusations, establishing intra and inter-community political relations. These exchanges are connected to matrimonial and commercial exchanges, not configuring an autonomous domain of inter social relations. However, given the importance of ritual exchanges in both regions, it is necessary to inquire and compare the principles that order them and their transformations in respective regional histories.
\end{abstract}


Keywords: Shamanism. Sub-middle San Francisco River. Lower Oiapoque River and Uaçá River.

\section{INTRODUÇÃO}

Este artigo tem por tema relações interindígenas de trocas baseadas no xamanismo em dois contextos etnográficos distintos onde há vinte anos venho pesquisando: submédio rio São Francisco e baixo rio Oiapoque e rio Uaçá, respectivamente na divisa Bahia/Pernambuco e fronteira Brasil/Guiana Francesa. Em ambas as regiões os intercâmbios interindígenas excedem o âmbito do xamanismo, mas encontram aí um dos principais vetores a sustentar redes de relações regionais, transnacionais e de longa duração (ANDRADE, 2007; 2008; 2012b; 2018) que colocam em evidência múltiplas dinâmicas intra e intercomunitárias, de maneira que as trocas entre os coletivos indígenas acontecem simultâneamento e nos mesmos circuitos das trocas estabelecidas com os espíritos auxiliares dos pajés (Karuãna e Encantados).

Penso o xamanismo como sistema de idéias e práticas, ou de pensamento e ação (BUTT, 1966), cujo propósito precípuo é produzir, por meio de técnicas e teorias diversas, a comunicação controlada entre distintos mundos, domínios ou camadas do cosmos a fim de permitir a continuidade da sociedade humana em meio a uma série de sociedades não humanas (de animais, de plantas, de artefatos, de mestres de espécies, de mortos, etc.), todas relacionadas em fluxos transformacionais que, simultaneamente, reafirmam as diferenças objetivas e a unidade na pessoa (sujeito) a elas subjacente (DESCOLA, 2013, pp. 5-13), possibilitando que o conhecimento produzido pelo xamanismo almeje "assumir o ponto de vista do que deve ser conhecido" (VIVEIROS DE CASTRO, 2004, p. 468), uma vez que "é preciso saber personificar, porque é preciso personificar para saber" (VIVEIROS DE CASTRO, 2002, p. 360). O xamanismo enquanto instituição social se ocuparia dos efeitos dos fluxos de energias, representadas pelas sociedades não humanas, sobre o bem estar dos humanos, procurando interferir em tais fluxos (LANGDON, 1992, p. 13). As dimensões ritual, política, terapêutica e religiosa do xamanismo revelam estratégias diferentes de gestão de relações com não humanos e necessitam ser analisadas de forma integrativa a fim de possibilitar que o xamanismo seja compreendido holisticamente (ib., p. 20)

\section{O BAIXO RIO OIAPOQUE E BACIA DO RIO UAÇÁ}

$\mathrm{Na}$ área compreendida entre os rios Oiapoque e Cassiporé, a BR-156 e o Parque Nacional do Cabo Orange, no extremo norte do estado do Amapá, estão as Terras Indígenas Uaçá, Galibi e Juminã, habitadas pelos índios Palikur, Galibi-Marworno, Galibi-Kali'na e Karipuna. São falantes, respectivamente, das línguas parikwaki (arawak), patois (pidgin originário da Guiana Francesa), galibi (karib) e patois, esta a língua franca da região, mais falada entre os índios que o português. O baixo Oiapoque passou a constar do território brasileiro apenas em 1900 a partir de um arbítrio internacional a favor do Brasil que pôs fim a uma antiga contestação francesa dos limites de seu território Ultramarino na América do Sul, estipulando-se o rio Oiapoque como fronteira natural entre as duas nações. Durante o longo tempo de vigência do território contestado cujos limites longitudinais iam do rio Branco (RR) ao Oceano Atlântico - a área em litígio esteve completamente aberta ao fluxo de pessoas originárias de 
diferentes nacionalidades e etnias que ora agiam politicamente como unidade autônoma, ora subordinavam-se a interesses do governo francês.

Essa região inclui a baía onde deságua o rio Oiapoque e a bacia do rio Uaçá, formada pelos afluentes Curipi e Urukauá e por uma rede de igarapés que alimenta lagos e lagoas. A foz do rio Uaçá, caracterizada pela presença de grandes manguezais, manifesta singular importância para a cosmologia dos Karipuna, Galibi-Marworno e Palikur, além de ser forte referência na obtenção de caranguejo e caramujo, proteínas complementes à caça e ao peixe.

Figura 1 - Localização das Terras Indígenas do Oiapoque, com suas respectivas aldeias

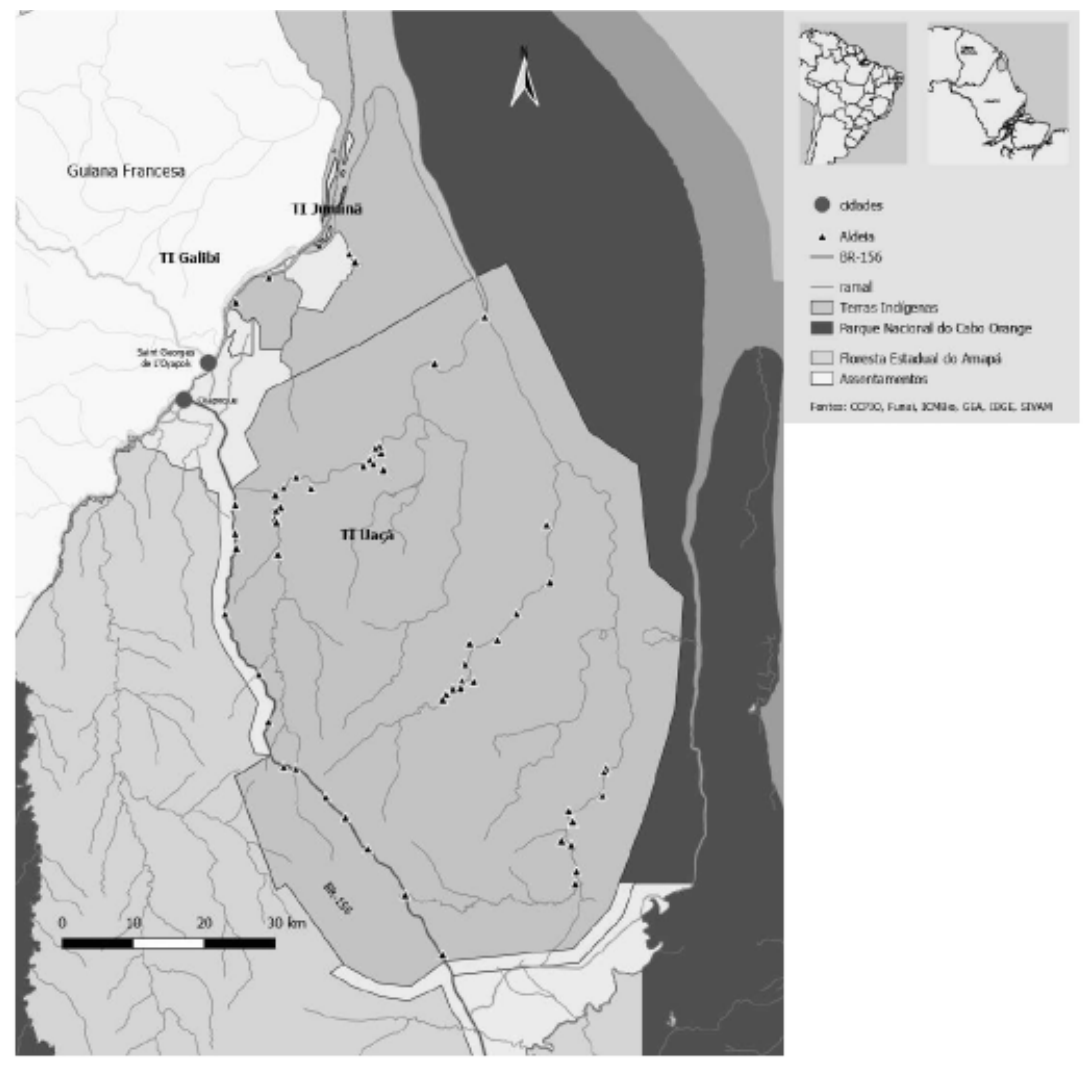

No que concerne à morfologia social, os Galibi-Marworno e Palikur tendem a seguir um padrão de residência uxorilocal, com o ideal de autonomia do núcleo familiar. Sem adotarem o mesmo padrão de residência, os Karipuna vêm ocupando novas áreas ao longo do rio Curipi e da BR 156 a partir da formação de assentamentos motivada pelo ideal da dispersão dos grupos locais com tendência pendular ao fechamento (adotando o casamento avuncular ou com primos patrilaterais como preferenciais) e à abertura (casando os homens com mulheres Galibi-Marworno ou as mulheres com brasileiros e franceses vizinhos das TIs Uaçá e Juminã) (TASSINARI, 2003). Os Palikur, com descendência patrilinear regida por regras de casamento entre seis clãs exogâmicos, proíbem, implicitamente, uniões entre todos os primos, exceto os paralelos patrilaterais, restando somente dois grupos casáveis para cada clã que poderão repetir as uniões entre si após quatro gerações (CAPIBERIBE, 2007, p. 67). Os clãs palikur são provavelmente oriundos de povos multilingues (PASSES, 2006, p. 76; GALLOIS-CEDI, 1983, p. 27) que passaram a adotar a organização social do grupo majoritário, de língua arawak. No passado esses clãs eram treze e hoje estão reduzidos a seis, mas preservando a descedencia patrilinear e a regra de casamentos fora do clã (CAPIBERIBE, 2007, pp. 67-69). 
Os núcleos domésticos Galibi-Marworno são denominados de $h \tilde{a}$ (VIDAL; TASSINARI, 2002, p. 4; TASSINARI, 2006, p. 19) e constituem-se de um casal $\alpha$, suas filhas casadas, seus maridos e os filhos desses casais, além dos filhos solteiros de $\alpha$. É definido pelos Galibi-Marworno como "um mutirão de pessoas" ou "um grupo que trabalha junto" (TASSINARI, 2006, p. 19) e podem manter-se unido até em ocasiões de escolhas eleitorais (VIDAL; TASSINARI, 2002, p. 6). Corresponde à unidade doméstica matrilocal presente na região das Guianas que conforma a autoridade dos sogros sobre os genros mediante $\mathrm{o}$ controle sobre suas filhas, sendo a uxorilocalidade "o meio pelo qual a família natal pode manter controle sobre as capacidades produtivas e reprodutivas de suas mulheres jovens" (RIVIÈRE, 2001, p. 68). Os pais da mulher do casal $\alpha$ podem ainda integrar o conjunto doméstico, mas é comum que passem a habitar uma outra residência quando velhos, de modo que dificilmente haverá quatro gerações co-habitando a mesma casa. Para os Galibi-Marworno, e também para os Palikur do Urukauá (CAPIBERIBE, 2007, p. 56), um casal recém formado e sem filhos habita a casa dos pais da mulher temporariamente, período em que o genro terá seu comportamento matrimonial "avaliado" pelos sogros e receberá do pai de sua esposa instruções complementares sobre como desempenhar com eficiência as atividades de subsistência necessárias à manutenção de sua família.

\section{SOBRE O XAMANISMO NAS RELAÇÕES REGIONAIS}

Dentre as múltiplas qualidades de trocas intra e inter regionais, as xamânicas mobilizam, com força e eloqüência, fluxos de colaboração e agressão. Relativamente às permutas xamânicas de colaboração, os primeiros registros etnográficos para a região foram realizados por Nimuendaju (1926) no contexto das interações entre Palikur,Waiãpi, Emerillon (Teko) e créoles $^{1}$ da Guiana francesa. Com os índios Waiãpi e Emerillon (ambos Tupi) do Camopi, região do alto rio Oiapoque, a cooperação é sublinhada pela transformação de espíritos de pajés desses povos em Yumawali $^{2}$ (ib., p. 47) homenageados com danças durante o turé (ib., 50). Os créoles do rio Oiapoque, ainda hoje reputados como bons feiticeiros e curadores, igualmente assistiam os antigos pajés palikur,"o que não raras vezes acontecia" (ib.; p. 49), durante sessões de cura e cantos. Inversamente, dinâmicas entre pajés palikur eram, até pouco antes da chegada de Nimuendaju à região do baixo Oiapoque e rio Uaçá, em 1925, lastreadas em acusações de feitiçaria que mobilizavam tensões entre os clãs palikur e terminavam, quase sempre, em assassinatos de pajés.

Por ocasião da presença de Nimuendaju, os Palikur frearam os atos belicosos motivados por acusações de feitiçaria, mas não esconderam as tensões intracomunitárias, uma vez que, sob a "atmosfera de harmonia e paz digna de nota" (ib., p. 40) que o etnólogo lá diz ter encontrado, persistiam o ódio e o desejo de vingança, em especial dirigidos aos grandes pajés locais, como Lexan Chevalier, exilados compulsoriamente com suas famílias nas ilhas do rio (ib., p. 48). A reputação desses pajés alcançava os índios galibi do rio Uaçáa que se deslocavam com freqüência ao Urukauá em busca de serviços xamânicos, hospedando-se com suas famílias na casa do pajé durante todo o tratamento, conforme testemunho de Nimuendaju (ib., p. 48).

Nos anos de 1960, Expedito Arnaud empreende, na qualidade de funcionário do SPI, incursões aos rios Urukauá, Uaçá e Curipi, sublinhando a tensão nas relações entre grupos locais palikur, galibi e karipuna devido às acusações de feitiçaria que produziam uma enorme desconfiança em relação aos pajés, mas não em relação ao xamanismo propriamente (ARNAUD, 1996, 
pp. 316-317). Arnaud corroborava, quarenta anos depois, as observações de Nimuendaju sobre o papel da agressão nas permutas xamânicas intracomunitárias na região. Os anos de 1950 e 1960 coincidem com o esgotamento dos tradicionais mecanismos de mitigação das tensões geradas pelas acusações de feitiçarias, em especial o exílio de pajés em novos assentamentos longe dos focos de tensão, conduzindo a assassinatos de pajés palikur ou de seus parentes. Esse tempo antecede à evangelização em massa dos Palikur, iniciada em meados dos anos de 1960 por um casal de missionários norte-americanos do Summer Institute of Linguistics (SIL) que, por doze anos, desenvolveu um trabalho de tradução da Bíblia para o parikwaki (CAPIBERIBE, 2007, pp. 166-167).

As permutas de agressões xamânicas e os serviços terapêuticos se estendiam para a vizinhança não-indígena, tanto da Guiana Francesa quanto do rio Cassiporé. Da Guiana vinham acusações de pajés Saramaká - ainda hoje procurados por índios brasileiros do baixo Oiapoque e rio Uaçá devido à reputação de deterem conhecimentos superiores de agressão e cura - contra pajés palikur, galibi e karipuna que habitavam as mesmas aldeias (ou vizinhas) de seus consulentes (ARNAUD, 1970, p. 15), acirrando as tensões intracomunitárias no baixo Oiapoque e rio Uaçá. As relações entre populações do baixo Oiapoque e da Guiana Francesa envolveram os Saramaká desde, provavelmente, a época em que esses chegaram ao rio Oiapoque, passando, em seguida, a explorar ouro na bacia do rio Uaçá e a comercializar aviamentos com os índios. Simultaneamente, alargavam as relações para as trocas matrimoniais e, certamente, xamânicas (ANDRADE, 2007, p. 105).

No que concerne às relações com os ribeirinhos do Cassiporé, no limite leste da TI Uaçá, elas concentram-se atualmente nas trocas comerciais, a exemplo dos batelões que, de dezembro a abril, quando a pesca do pirarucu é suspensa, adentram o rio Uaçá a fim de vender nas aldeias o peixe salgado. Os índios, por sua vez, vendem farinha, goma e beiju a esses atravessadores que, buscando os produtos nas aldeias, tornam-se uma interessante alternativa ao comércio nas distantes cidades de Oiapoque e Saint Georges (ANDRADE, 2007, p. 105). Tais relações comerciais contemporâneas foram precedidas pela prestação de serviços terapêuticos por pajés galibi que atendiam nas vilas ao longo do rio Cassiporé, expediente vantajoso para eles, uma vez que recebiam pagamentos em dinheiro ou em bens materiais, não usuais no Uaçá (ARNAUD, 1970, p. 11). Aqui os serviços dos antigos pajés galibi do rio Uaçá foram, provavelmente, o motor para outros contextos de permutas com as comunidades ribeirinhas do Cassiporé, atualizados em especial pelo comércio sazonal de peixe salgado e pelo intercâmbio esporadicamente realizado entre as escolas da aldeia galibi-marworno Tukay, na BR-156, e da vila do Cassiporé.

Relato ainda outros dois cenários de permutas interregionais ensejadas pelo xamanismo e que relacionam os Karipuna, Palikur, Saramaká e índios do alto Oiapoque. O primeiro desses contextos refere-se à iniciação, no final dos anos de 1950, do grande pajé karipuna Aniká pelos pajés Panô (Saramaká, de alta reputação), Kaimã, Anapi e Chandele, índios waiãpi ou emerillon do rio Camopi (ANDRADE, 2018, pp. 216-217). O segundo cenário é sobre a amizade entre o pajé palikur Guiome e Kaimã, iniciada com o deslocamento dos índios do alto para o baixo Oiapoque, conforme narrativa de Uwet, neto de Guiome:

Ele ficou quase dois anos aqui. Quando ele chegou foi lá com meu vovô (o pajé Guiome), ficou lá com ele trabalhando, fazendo farinha muita aqui. Teve muita pessoa que veio aqui. Kaimã chegou com maracá grande dele, de manhã cedo, do Oiapoque. Foi pra casa de meu vovô e pediu licença pra cantar. Tirou o maracá dele e cantou (Uwet imita o som grave de um canto monotônico). Meu vovô ficou escutando ele (in ANDRADE, 2007, pp. 120-121). 
Uwet segue contando que Kaimã desceu o rio Oiapoque com mais 25 pessoas, em fuga de ataques de índios inimigos que destruíram sua aldeia e os fizeram perder o conhecimento das etapas de produção da farinha de mandioca. Daí eles terem ido parar no rio Urukauá no intuito de "procurar aqui como fazia farinha para levarem pro pessoal deles" (in ANDRADE, 2007, p. 121).

No tempo atual, as permutas xamânicas inter-regionais são desempenhadas por pajés galibi-marworno e karipuna e tendem a dar mais espaço à agressão (na forma de feitiços, doenças, ataques de espíritos auxiliares, etc.) oriunda do alto Oiapoque, não obstante conservarem a cooperação por intermédio da presença de Karuãna ${ }^{5}$ waiãpi (ou emerillon) no plantel de espíritos auxiliares dos pajés da região. A atividade xamânica continua atuante nas aldeias principais do rio Curipi (Manga, Espírito Santo e Santa Izabel) e do rio Uaçá (Kumarumã); todavia, o uso dos potás ou suflê, espécie de breathing sorcery ou evil spells (WRIGHT, 2004, p. 89; BUCHILLET, 2004, p. 111), é comum entre os índios do Oiapoque (até entre os evangélicos Palikur), sendo normalmente associado à prática da feitiçaria. Como prescindem de relações com os Karuãna, posto ser, basicamente, uma técnica mnemônica cuja eficácia decorre da conjunção do sopro com a recitação em segredo de fórmulas incantatórias, os potás não configuram atividade xamânica clássica, não obstante rivalizarem com o xamanismo enquanto recurso de agressão.

Se o xamanismo continua operante na região do baixo Oiapoque e bacia do rio Uaçá, experimenta nos dias de hoje o arrefecimento das sessões de cantos e cura (xitotós ou cantarolas), tradicionalmente de ocorrência regular nas principais aldeias galibi-marworno e karipuna, em função, sobretudo, do avanço das igrejas evangélicas nos rios Uaçá e Curipi. Tais igrejas, de denominações diferentes, arrebanham os assistentes dos pajés (incluindo as koiaminãs, mulheres cantadoras, e os palikás, assistentes principais) e suas famílias, dificultando a realização do rito. Como o turé $e^{6}$ goza de prestígio e reconhecimento geral entre os povos indígenas do Oiapoque, sua realização vem sendo preservada e mesmo aquecida pelo interesse dos jovens, alguns deles estudantes da licenciatura indígena do campus de Oiapoque da Universidade Federal do Amapá (UNIFAP). Esse interesse pelo xamanismo foi recentemente ilustrado durante o VI Encontro dos jovens indígenas do Oiapoque, realizado na aldeia karipuna Santa Isabel em agosto de 2019. Na ocasião houve a encenação de uma cura xamanística e invocação dos espíritos auxiliares, realizada com o apoio de um pajé local, apresentação denominada pelos atores de "chamamento dos Kahuan". Como costuma acontecer com o turé realizado no dia do índio e em outras datas comemorativas, seguiram-se especulações sobre ser ou não, do ponto de vista dos Karuãna, apenas uma "encenação", agravada pela tempestade que interrompeu o resto da programação e foi logo interpretada como possível reação dos Karuãna. ${ }^{7}$ Esse novo interesse no xamanismo regional (talvez, apenas mais um ciclo de sua revigoração) pode ensejar a emergência de jovens pajés em conflito com as tradicionais lideranças rituais e seu controle sobre $o$ processo de iniciação. Somente o tempo poderá dizer se esses jovens oficiantes fixar-se-ão enquanto pajés ou não

Vejamos agora o segundo contexto etnográfico em tela neste artigo.

\section{O SUBMÉDIO SÃO FRANCISCO}

Utilizarei aqui um recorte do universo das relações interindígenas na região do submédio São Francisco, próximo à divisa $\mathrm{BA} / \mathrm{PE} / \mathrm{AL}$, focando os Tumbalalá como um dos vários pontos densos de um complexo regional de redes de trocas vigentes na longa duração. Enquanto uma nova alteridade, 
esse coletivo é produto da confluência de tal complexo com um campo multi institucional contemporâneo no qual o poder de definição nas narrativas sobre sua história é controlado pelo capital simbólico - convertido em poder de enunciação (BOURDIEU, 1998[1989]) - acumulado por algumas famílias tumbalalá ao longo da história de permutas com os Truká (PE), Tuxá (BA), Atikum (PE), Fulni-ô (PE) e famílias do Caxoí e Ilha das Vargens (PE), hoje autodenominadas Tuxí.

A vasta região do submédio rio São Francisco é coabitada por diversos coletivos indígenas cujas histórias estão, quase sempre, associadas às missões insulares aí instaladas a partir do século XVII e extintas em períodos distintos, corroborando e reinventando circuitos de reciprocidades interindígenas que provavelmente já existiam antes da presença colonial. Se a presença colonial na América indígena produziu novos arranjos sociais, i. e., ensejou e decantação de coletivos fluidos em "grupos" organizados segundo critérios étnicos, como é, por exemplo, a leitura de BOCCARA (2001) - simultaneamente à fulminação de outros coletivos, sobretudo com a escravização e a atividade missionária -é porque ela foi agregada às dinâmicas de relações interindígenas, e não porque foi a sua causa (ANDRADE, 2008). Assim, são as redes de relações sociais de trocas multiqualitativas que ressaltam uma história regional de longa duração, motivo pelo qual os coletivos indígenas na região do submédio São Francisco devem ser dentro e a partir delas compreendidos em suas trajetórias e multiplicidades contemporâneas (ANDRADE, 2008).

Figura 2 - Localização dos povos indígenas na região do submédio rio São Francisco

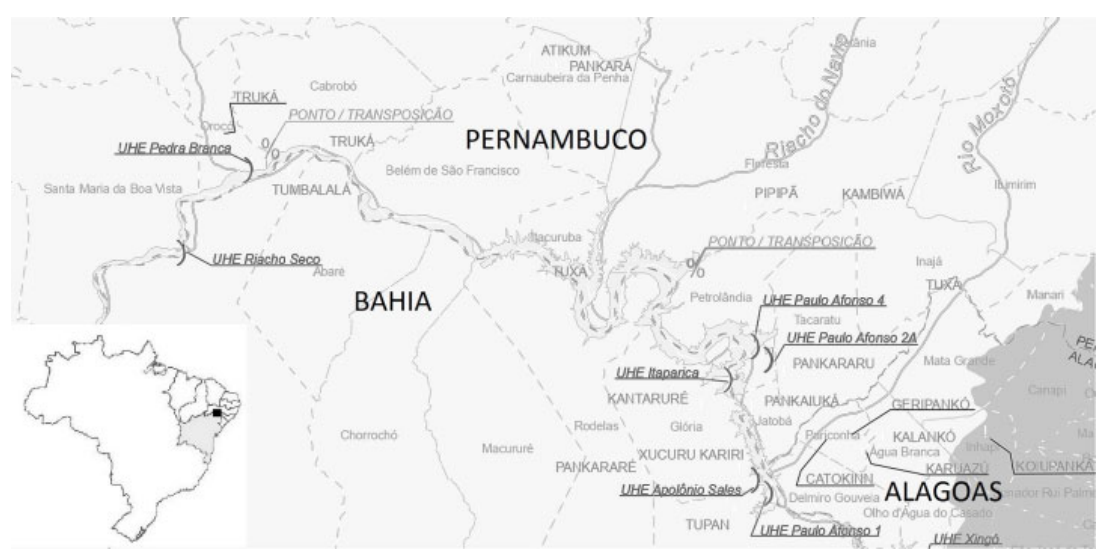

Fonte: Mapa da bacia hidrográfica do rio São Francisco - Povos indígenas e barragens / Secretaria de Meio Ambiente e recursos hídricos da Bahia (modificado).

Partindo dos Tumbalalá da região de Pambu (BA), considerarei as reciprocidades historicamente instituídas com os Truká da Ilha da Assunção (PE) e os Tuxá de Rodelas (BA), concentrando-me nas de ordem ritual que gravitam em torno do complexo do toré. ${ }^{8}$ Essas estão associadas a outras qualidades de trocas, de modo que são mutuamente determinantes, e o recorte aqui produzido é tão somente analítico. As relações de permutas rituais entre Truká e Tuxá são mais fortes, pois lastreadas no parentesco por ambos reconhecido. Tal ligação sustentaria a continuidade de trocas matrimoniais, rituais e políticas:

Para começar, a minha avó era descendente dos Truká. Meu avô casou com ela e trouxe pra'qui, para os Tuxá. Mas daí então quando meu avô começou a procurar o direito dele, aí ele ia até o Rio de Janeiro. Eu não era nem nascido. Minha mãe já era nascida, só que era criancinha. Quando ele foi a primeira vez para o Rio, a velha estava doente, a mãe de minha mãe, e ele foi com ela e deixou lá com a família, nos Truká" 
Lá tem os Proká-Truká do tronco da jurema, são os cabocos de lá da Assunção. São amigos dos Tuxá. Podemos conviver bem. Eu mesmo já morei lá 12 anos. Conheço tudo, da ponta da ilha de cima até a parte de baixo (CACIQUE TUXÁ DOS ANOS 70. In: SAMPAIO-SILVA, 1997, p. 173).

No início, as relações de permutas rituais e de solidariedade entre os Tumbalalá e Tuxá foram mediadas pelos Truká; foi também por meio deles que os Tumbalalá acessaram as redes de relações com outros povos do submédio rio São Francisco, a exemplo dos Atikum. No tempo atual as relações dos Tumbalalá com os Tuxá são sustentadas pelo reconhecimento de contigüidades culturais entre ambos:

A gente foi a Tumbalalá depois que tomamos conhecimento do pessoal Tumbalalá procurando sua reivindicação. Como nós somos de uma aldeia, a terceira aldeia reconhecida desse nordeste e a primeira na Bahia, tomamos conhecimento que Tumbalalá pode até fazer parte da nossa tribo (BIDU, CACIQUE TUXÁ DE RODELAS. In: BATISTA, 2001, p. 53).

Não obstante o caráter coletivo das representações formuladas pelos Truká, Tuxá e Tumbalalá a respeito das permutas rituais, elas não são totais e alcançam um número restrito de núcleos domésticos ou indivíduos que efetivamente participam das redes regionais de trocas interindígenas, constituídas, por sua vez, por níveis de redes (ou subredes) que incluem imediatamente os Pankararu, Pankaru, Fulni-ô e Pankararé, mas expandem (ou contraem) na seqüência dos vários circuitos de comunicação dos quais participam os povos indígenas do Nordeste, a exemplo de encontros nacionais, manifestações e movimentos em defesa de direitos territoriais organizados por entidades como o Conselho Indigenista Missionário (CIMI), a articulação dos Povos Indígenas do Brasil (APIB), a Coordenação das Organizações Indígenas da Amazônia Brasileira (COIAB) e a Articulação dos Povos e Organizações Indígenas do Nordeste, Minas Gerais e Espírito Santo (APOINME).

Tais movimentos constituem níveis mais inclusivos de redes, com a presença de coletivos indígenas de praticamente todas as regiões do Brasil, e representam ocasiões oportunas para o início, consolidação ou ampliação de trocas multiqualitativas, em especial de apoio, de solidariedade (sobretudo no que concerne a ameaça de direitos territoriais em situações específicas) e de cantos xamânicos, conforme assinalou certa vez o mestre de toré tumbalalá Aprígio Fatum - que frequentara algumas assembléias, reuniões e manifestações indígenas em Brasília, Paulo Afonso, Salvador e Porto Seguro - a fim de explicar-me como aprendera cantos de origem Pataxó e de índios do Parque do Xingu. Uma parte desse repertório dinâmico de cantos trocados durante interações nas mobilizações do movimento indígena é incorporada ao toré tumbalalá quando um participante, no momento apropriado do rito, tira uma linha de seu gosto, seguindo-se de comentários sobre o canto novo e que poderão aprová-lo ou não, definindo a possibilidade de ser cantado por outrem nas ocasiões rituais subseqüentes. No que concerne à memória da origem de um canto de toré, os Tumbalalá do núcleo do São Miguel, cuja história das trocas rituais é mais antiga e robusta, não apresentam objeção alguma à idéia de que o seu toré possui linhas e Encantados oriundos de diferentes povos do submédio rio São Francisco ou de fora desta região. Ao contrário: parecem ciosos de que quanto mais cantos e Encantados de fora e de longe melhor, posto que a presença de ambos no 
complexo xamânico desse núcleo político-ritual revela a participação antiga e intensa da família Fatum e aliados nas redes regionais interindígenas de trocas.

Entretanto, o diálogo mediante as trocas históricas entre os Tuxá, Truká e Tumbalalá mostra que suas relações configuram muito claramente representações pontuais a cerca da contigüidade entre estes povos e - invertendo-se os atributos, mas mantendo-se a mesma lógica da reciprocidade - das rupturas. A memória dessas contiguidades é exemplificada de forma eloquente nos desempenhos rituais, conforme se vê no seguinte trecho de uma linha de toré truká:

\author{
Adeus, Casa Grande \\ Adeus sentinela \\ Eu vou buscar minha tribo \\ Dentro da aldeia de Rodelas.
}

Embora as relações de apoio estejam evidentes tanto no presente quanto no passado da história das relações entre estes grupos, a disputa por capital ritual é a contrapartida imediata delas. O ensinamento de segredos rituais e a antiguidade de uma aldeia revelada na comunicação com os Encantado podem estimular um grupo a ocupar a posição de tronco (matriz) dos galhos ou ramas, novos grupos detentores de uma ciência (conhecimento do toré) menos elaborada. Tal concorrência é mais presente entre os Truká e Tumbalalá, provavelmente devido à proximidade geográfica, histórica e matrimonial, dispondo as rupturas circunstanciais sob o mesmo estatuto de reciprocidade que comanda as relações de contiguidade (ANDRADE, 2008, p. 196). Na rede de comunicação da qual fazem parte, dentre outros povos, os Tumbalalá, Truká e Tuxá, as relações pacíficas e hostis se sobrepõem e dependem de dois fatores fundamentais: os contextos em que elas se desenrolam e os atores envolvidos (quais famílias ou indivíduos).

\title{
FINAL: CONSIDERANDO REDES XAMÂNICAS REGIONAIS
}

Tendo apresentado, sinteticamente e em seus respectivos recortes, as redes de trocas lastreadas no xamanismo do baixo rio Oiapoque/rio Uaçá e submédio rio São Francisco, tentarei agora considerá-las conjuntamente, refletindo sobre elas e olhando-as com atenção em suas possíveis semelhanças e singularidades. Não se trata, entretanto, de compará-las, processo mais refinado e que demandaria espaço maior do que dispomos aqui, uma vez que, enquanto método analítico, a comparação - e em especial, a comparação etnológica - deve construir os comparáveis por meio do movimento de "desmontar e remontar lógicas parciais de pensamento" (DETIENNE, 2004, p. 16), destoando das crenças na independência, em relação ao observador, das propriedades de objetos previamente comparáveis.

O primeiro ponto em comum a se destacar é que não convém pensar em relações entre grupos enquanto unidades sociais coesas e acabadas. Grupos sociais são abstrações socio-lógicas restritas e operadores conceituais enquanto que as relações de trocas são travadas no campo da prática de sujeitos concretos que apresentam formas diversas de classificar e representar as mesmas alteridades (ANDRADE, 2008, p. 198). Os agentes de trocas são indivíduos ou grupos de indivíduos baseados quase sempre no parentesco e não unidades sociais vis-à-vis (GALLOIS, 2005, p. 25). 
O segundo ponto está direcionado aos elementos das trocas ou aos conteúdos do diálogo interindígena. Em um gradiente qualitativo, as trocas no baixo Oiapoque e rio Uaçá e no submédio São Francisco podem ser tanto de apoio político, mulheres, bens, conhecimentos rituais, cantos xamânicos, etc. quanto de acusações de feitiçaria ou de inépcia ritual que muito raramente resultam em agressões mais significativas, o que, de resto, corrobora largamente os exemplos disponíveis em outras regiões etnográficas. O terceiro ponto mostra que a comunicação interindígena desenvolve-se em planos complexos, circunstanciais e coextensivos, haja vista que, como se disse, elas são fruto de trocas entre famílias, indivíduos ou grupos de indivíduos e não um diálogo uníssono entre unidades sociais fechadas e delimitadas. Indivíduos e parentelas participando de redes de trocas alargam suas próprias fronteiras e produzem uma cultura regional como um processo ou fluxo não estruturado de símbolos (HANNERZ, 1992).

No baixo Oiapoque e rio Uaçá as permutas situadas no xamanismo são, a semelhança do que ocorre no submédio São Francisco, de ordens que poderíamos chamar de "positivas" e "negativas" (LIMA; CÓRDOBA, 2011, p. 16), não obstante serem ambas constitutivas do próprio xamanismo e, a rigor, sintetizada pelas capacidades de cura e de agressão da empresa xamânica (ANDRADE, 2016, p. 185). Estas competências não podem ser exercidas separadamente, uma vez que apenas no discurso etnificado sobre o xamanismo regional é que a feitiçaria e a cura emergem como domínios autônomos e separados, discurso cuja versão "nativa" é encontrada nas declarações públicas de pajés e mestres de toré que afirmam acionar seus conhecimentos apenas para promoverem curas de doenças e "fazer o bem", ao mesmo tempo que acusam oficiantes rivais, próximos e individualizados ou distantes e difusos, de promoverem a feitiçaria e o mal. Tal discurso etnificado é, entretanto, confrontado pela prática ritual que corrobora a complementaridade entre agressão e cura, conforme ilustram as narrativas a seguir:

[...] o índio, ele tem uma parte tola, não sabe? Ele tem uma parte tola. [Podia trabalhar com xangô ${ }^{9}$ ], mas quando estivesse tudo regimado [...] Ele (Acilon Ciriaco, cacique Truká) não trabalhava, ele não trabalhava nisso não. Ele é que dizia, quando estivesse tudo regimado, a aldeia estivesse bem prosperada, estivesse com todo... podia ser, não era? Aí o índio podia trabalhar no outro trabalho pra se defender. (APRÍGIO FATUM, MESTRE DE TORÉ TUMBALALÁ. In: ANDRADE, 2008, p. 222).

[...] Em português você já sabe que é feitiçaria, mas para nós é piaii, pajé que chama. [...] Piaii, faz bem e faz mal. É a mesma coisa. Tem canto pra fazer bem, tem pra fazer mal. É como um enfermeiro. É a mesma coisa, pode anotar. Um enfermeiro, se quiser curar a pessoa, tem remédio para fazer bem; se ele quiser lhe matar, dá uma injeção de calmante e acaba com você na hora. É um piaii, é um pajé. É um curador e pode lhe matar também. Assim é a mesma coisa conosco aqui. Sabe assoprar pra fazer bem e na mesma hora pode lhe matar. (GETÚLIO, CANTADOR GALIBI-MARWORNO. In: ANDRADE, 2007, pp. 8788).

As permutas "positivas" e "negativas" - correspondendo, respectivamente, às trocas de conhecimento, cantos, grafismos, iniciação no xamanismo, etc., de um lado e às agressões entre pajés, acusações de feitiçaria, etc., do outro - estão presentes como marcadoras do próprio xamanismo. No pólo das permutas negativas, as acusações de feitiçaria e de inépcia ritual são as formas prevalentes, seguidas de roubos de cantos e de padrões gráficos (para o baixo Oiapoque e bacia do rio Uaçá). Cantos e grafismos importam porque eles são 
dádivas, senhas e registros de relações com os Encantados e Karuãna, sendo apropriados diferentemente em ambas as regiões etnográficas, uma vez que, enquanto no baixo Oiapoque e rio Uaçá os pajés são ciosos de seus repertórios particulares de cantos, no submédio São Francisco investem tanto nos repertórios locais - representados por dádivas de Encantados de um terreiro de toré, de uma aldeia ou de um coletivo indígena em geral - quanto nas linhas de toré aprendidas com outros povos, empenhando-se em sublinhar que seus respectivos núcleos rituais participam de circuitos regionais de comunicação formados por humanos e não humanos de diferentes povos/lugares no cosmos.

No que concerne aos Tumbalalá em geral e em especial às famílias do núcleo do São Miguel, a prática ritual espelha, ou melhor, ela é a facilitadora de permutas de apoio político ao longo da história das relações interindígenas no submédio rio São Francisco. Aqui, em função dos movimentos por identidade - que remontam aos anos 40 do último século - os desempenhos rituais passaram a operar como o principal componente de fronteiras, função ensejada (e desejada) pelo próprio Estado. Por conta disso, a mediação cosmopolítica da ação xamânica foi depurando-se em mediação política, a ponto do toré ser "reduzido", em certas circunstâncias, a "expressão de indianidade", transformando-se a política dos rituais em rituais da política de identidade. Essa redução, entretanto, ocorreu mais por conta de escolhas analíticas sobre o xamanismo no Nordeste indígena que por ação dos atores sociais nele envolvidos, uma vez que sendo o xamanismo regional a forma de relação entre humanos e Encantados, ele se impõe enquanto modelo co-extensivo de relações interhumanas, importanto menos a qualidade dos termos relacionados (Encantados $\mathrm{e}$ humanos) que o próprio fato da relação. $\mathrm{O}$ xamanismo regional, operando por meio das redes de comunicação interindígenas, é uma espécie de consciência histórica de relações cosmopolíticas, de tal forma que, sendo um modelo fractal de produção do alter e do mesmo, encontra-se presente nas escalas micro e macropolíticas, conferindo-lhes unidade (CARNEIRO DA CUNHA, 1998, p. 9). Assim, das acusações de inepcia ritual trocadas entre famílias tumbalalá à solidariedade nas mobilizações por território e identidade que articulam-se nas redes de trocas interindígenas regionais ou nacionais, das quais fazem parte os povos do submédio São Francisco, há uma completude subjascente que permite pensar nesses diferentes níveis de redes em termos homólogos, conforme ilustra o diálogo abaixo que mantive no ano de 2000 com três pessoas do núcleo tumbalalá do São Miguel:

Áurea Fatum - Os Encantados das outras aldeias, os Encantados das outras aldeias vêm trabalhar aqui.

Cícero Marinheiro - É, nós trabalhamos com os Encantos da aldeia daqui e de outras aldeia também.

Áurea Fatum - Essa linha aí mesmo, que Cícero cantou, é do Encanto de outra aldeia, não é? Ele vem trabalhar aqui.

Aprígio Fatum - É, é daí da Serra do Umã [...]

Áurea Fatum - A quatrinha que eles cantam lá no Belém, canta aqui também $[\ldots]$

Cícero Marinheiro - Belém, São Francisco, tem uma ilha (da Vargem), que é uma aldeia...

Áurea Fatum - Tem, mas eles (os Encantados) vêm aqui [...]

Aprígio Fatum - Oh Cícero, essa aldeia do Caxoí, tá continuando?

Cícero Marinheiro - No Caxoí, no Caxoí o pessoal diz que tem um toré no Caxoí, dizem que tem, mas deve ser sobre a ilha da Vargem, não é? Que a ilha da Vargem é que é aldeia. 
Revelando unidade em torno da relação cujos termos são humanos e não humanos, o diálogo flui entre a circulação de Encantados e linhas de toré e a sequência de tradições por meio das sociogêneses regionais, algo marcante na pergunta de Aprígio Fatum sobre a continuidade da "aldeia do Caxoí", ligada à antiga missão do Beato Serafim na ilha das Vargens ou da Vargea (ANDRADE, 2008, pp. 140 e 376), em Pernambuco, e que hoje abriga os autodenominados Tuxí, um dos últimos "emergentes" nessa porção do rio São Francisco. Passar do micro ao macro, das relações estritamente rituais (se é possivel assim dizer...) às geradas no âmbito das políticas de identidade não é um problema, uma vez que esses distintos níveis de, às vezes, uma mesma rede são transformações uns dos outros. Tais transformações sinalizam que a "conexão evidente e imperativa entre homens e Encantado sublinha que qualquer possibilidade de produção contingente de conteúdos culturais passa pelas trocas simbólicas reativadas com a sobrenatureza, demonstrando o lugar das cosmologias nas etnogêneses no nordeste indígena. É a elas que se retorna a fim de (re)produzir a cultura e se desvencilhar do hiato estabelecido com elas mesmas" (ANDRADE, 2008, p. 310).

Relativamente às trocas xamânicas "negativas"10 - basicamente associadas às acusações de feitiçaria, de roubos de cantos e de grafismos e de inépcia ritual - no submédio São Francisco elas tendem a se concentrar nas acusações de inépcia ritual, serem de natureza intracomunitárias (i.e., acusa-se alguém próximo) e, assim, comporem redes ou subredes distintas, uma vez que, em geral e não como regra, os circuitos das acusações são diferenciados daqueles das solidariedades, transcorrendo que entre parceiros de trocas "negativas", obstam-se trocas "positivas", não obstante acusações de inepcia ritual e aliança matrimonial serem possíveis para os mesmos parceiros. A excessão também vale para acusações de feitiçaria (trabalho de xangô) dirigidas aos Tuká da ilha da Assunção, defronte ao território dos Tumbalalá. Todavia, tais acusações não são feitas aos Truká em geral, mas a segmentos ou subgrupos político-rituais, da mesma forma que os acusadores não são os Tumbalalá em geral, mas pessoas vinculadas, por descendencia ou fidelidade ritual, a um de seus núcleos. $\mathrm{O}$ mesmo pode-se afirmar sobre os Truká: dirigem acusações ou não de inépcia ritual aos Tumbalalá conforme a pertença aos subgrupos político-rituais. Portanto, no submédio São Francisco, as relações em torno das trocas "negativas", assim como em torno das trocas "positivas", são entre segmentos intracomunitários lastreados no parentesco e na atividade ritual, revelando a inocuidade de se considerar "grupos étnicos" enquanto sujeitos de tais relações.

No baixo Oiapoque e rio Uaçá as acusações de feitiçaria, de inépcia ritual e de roubos de cantos e de grafismos circulam conjuntamente às trocas "positivas", de maneira que todas elas podem ser dirigidas aos mesmos parceiros concretos ou potenciais. Aqui é necessário distinguir duas formas de agressão por feitiçaria: aquela produzida por ação de um Karuãna que age como patógeno canibal enviado por um pajé e aquela produzida por meio dos potás, formulárias incantatórias para múltiplas finalidades, recitadas em segredo e assopradas. A primeira é tipica do xamanismo regional e utiliza o consórcio com os espíritos auxiliares, enquanto a outra consiste em uma técnica de produção de efeitos por meio do sopro e da manipulação da intencionalidade da palavra (ANDRADE, 2012a, p. 980). Apenas os pajés estão habilitados a manterem relações com os Karuãna, de modo que a feitiçaria por este meio é sua prerrogativa, quase sempre associada à geração de doenças. Os potás, por outro lado, exigem apenas recursos mnemônicos para decorar as fórmulas incantatórias, além, é claro, de alguém que as ensine. Tais fórmulas, quando visam à feitiçaria, aludem a coisas perigosas, a exemplo de animais peçonhentos, e podem constituir repertórios privados transmitidos dentro do grupo de descendencia (BUCHILLET, 2004, pp. 118-119) ou serem de domínio mais amplo (VIDAL; 
WHITEHEAD, 2004, p. 63; WILBERT, 2004, p. 38; WRIGHT, 2004, p. 89). Seja como for, a recorrência e facilidade de uso desse tipo de breathing sorcery faz com que os potás e os sopradores (seus praticantes) sejam temidos no baixo Oiapoque e rio Uaçá, evitando-se aldeias da região com fama de concentrarem tais atividades; algumas, dizem, a ponto de crianças aprenderem as fórmulas ao escutarem, involuntariamente, sendo transmitidas a terceiros. No entanto e conforme os Galibi-Marworno, os mais perigosos potás vêm de longe, em especial do Suriname, onde são oferecidos de porta em porta ou circulam facilmente, sendo vendidos na rua "como picolé".

Da diferença entre essas duas modalidades de feitiçaria decorre que um feitiço pode vir de perto ou de longe, a depender de como foi gerado. ${ }^{11}$ Os que utilizam patógenos canibais têm a sua autoria quase sempre associada a pajés de povos distantes, tais como os Waiãpi e os Saramaká da Guiana Francesa e os Wayana e Aparaí do Suriname. Feitiços gerados por potás são mais complicados, devido à facilidade em produzí-los, e há grande possibilidade, para os Galibi-Marworno, de seus autores serem do próprio grupo de residencia matrilocal. Nesse caso, a agressão emergirá entre pessoas ligas por relações dos tipos WF-DH / WM-DH / ZH-WB e mais ramente WZH-WZH, manifestando-se, portanto, entre aqueles com afinidade concretizada, diferentemente do que se passa para os Tumbalalá, cujas trocas de acusação de inépcia ritual ocorrem entre afins potenciais (os que, prefencialmente, moram em aldeias diferentes), tendendo a arrefecer com a consumação da relação de aliança.

Note-se ainda que no grupo de residencia matrilocal galibi-marworno deve prevalecer a cooperação entre seus membros, que tratam-se por termos de parentesco consanguíneos ou consanguinizadores, exatamente como estratégia de administrar o risco proveniente da co-residência entre afins (ANDRADE, 2007, pp. 36-38), o que, conforme argumentado, é insuficiente para evitar a feitiçaria no seio do grupo de residência. Por seu turno, acusações de roubos de cantos xamânicos e de grafismos, ambos dádivas dos Karuãna, são feitas em relação a pajés: as primeiras a pajés próximos geograficamente, pois precisam escutar os cantos, e as outras feitas difusamente a pajés próximos ou distantes, dada a possibilidade dos padrões gráficos circularem indefinidamente por meio de fotografias.

Essas são algumas das características gerais das trocas xamânicas, "positivas e "negativas", nas redes de relações interindígenas no baixo Oipoque e rio Uaçá e no submédio São Francisco, devendo ser qualificadas a partir de um momento, mas tendo em vista as transformações ensejadas por eventos localizados nas histórias regionais, pois as intenças trocas interclânicas de acusação de feitiçaria, quase sempre terminadas em assassinatos de pajés, entre os Palikur de outrora; ou os intercâmbios rituais, nos anos de 1940, entre o núcleo tumbalalá do São Miguel, o grupo político truká de Acilon Ciriaco e os Atikum de Serra do Umã; ou ainda a prestação de serviços terapêuticos por pajés do rio Uaçá feita a ribeirinhos do rio Cassiporé, são manifestações temporais de fluxos de relações moldados pela história regional, especialmente pela história de contato com missões, SPI, FUNAI e demais agentes não indígenas capazes de impactarem definitivamente as trocas xamânicas regionais, seja a elas agregando bens e conhecimentos ou produzindo novas regras a fim de administrar relações entre coletivos indígenas. Mas é em função desses eventos históricos, a um só tempo transversais e constitutivos do universo ameríndio, que as redes interindígenas de trocas xamânicas no baixo Oiapoque e rio Uaçá e no submédio São Francisco estão aí, indissociáveis, em um certo sentido, das redes regionais de relações com não índios, pois são nas redes de relações que se deve procurar "quaisquer indícios de permanência, durabilidade e contigüidade associadas 
a uma história regional de longa duração assentada nas trocas entre coletivos humanos e entre esses e a sobrenatureza" (ANDRADE, 2008, p. 309).

\section{NOTAS}

${ }^{1}$ Os creóles não formam um coletivo particular, mas uma mescla difusa e análoga aos ribeirinhos amazônicos brasileiros. Diferenciam-se e são diferenciados dos negros Saramaká, esses sim passíveis de serem caracterizados enquanto "grupo étnico", com memória particular de origem e potencial mobilizador.

${ }^{2}$ Os Yumawalí possuem um céu próprio (Yinoklin), embora morem nas montanhas ao longo do rio Uarukauá, e são os espíritos auxiliares dos pajés palikur de outrora que persistem na cosmologia evangelizada desse povo. Numerosos, apresentam-se sob a forma de pássaros Tukumaská e são os inventores de importantes artefatos rituais (Nimuendaju, 1926, pp. 46-47).

${ }^{3}$ Nos anos de 1980, os índios Galibi do rio Uaçá passaram a adotar o autoreferente Galibi-Marworno a fim de se diferenciarem dos Galibi (depois Galibi-Kali'na) do rio Oiapoque, população pequena que lá chegou, vinda do litoral da Guiana Francesa, em 1950 (VIDAL, 2000).

${ }^{4}$ A razão do deslocamento do grupo liderado por Kaimã foi fornecida, em interlocução paralela com Uwet, por Hélio Labonté, índio palikur que traduzia trechos da conversa. Malcher (2019, p. 248) menciona um tuxaua emerillon (chamado Caimã) que, em função de brigas provocadas por divergências internas, deixou a Guiana Francesa com um grupo de índios e buscou refúgio junto à Inspetoria do SPI no alto Oiapoque. Teria este líder do alto Oiapoque, após o aval do SPI, descido o rio e alcançado o Urukauá com seus congêneres?

${ }^{5}$ Versão galibi-marworno e karipuna dos Yumawali palikur.

${ }^{6}$ Rito amplamente presente na região das Guianas e que, no baixo Oiapoque e bacia do rio Uaçá, pode ser sintetizado com uma festa, com dois dias de danças e caxiri, ofertada aos Karuãna para que eles continuem a aliança com um pajé, possibilitando que este prossiga com as atividades de cura (enunciadas) e agressão (segredadas).

${ }^{7}$ Baseio-me em relato feito por Rita Lewkowicz, coordenadora do Programa Oiapoque do Iepé - Instituto de pesquisa e formação indígena.

${ }^{8}$ Embora quase homônimos toré e turé são ritos distintos em termos de performances, seqüências e parafernália empregada em sua execução. As similitudes - tais como presença de espíritos auxiliares do pajé, uso de tabaco e bebida (respectivamente vinho da jurema e caxiri), referencia a um ponto central no espaço do desempenho ritual (o cruzeiro no terreiro e o mastro no lakhu) e o desdobramento do rito em etapas privadas (chamadas particular e xitotó) - são constitutivas dos complexos rituais xamânicos em geral (ELIADE, 1986; LANGDON, 1996; MÉTRAUX, 1944). Portanto, elas são insuficientes para, conjuntamente aos nomes, sugerir conexões históricas ou derivações entre o toré dos índios do Nordeste e o turé da região etnográfica das Guianas.

${ }^{9}$ Nome para variações regionais do candomblé.

${ }^{10} \mathrm{O}$ termo é usado aqui com parcimônio, pois sendo agressão e cura atos coextensivos no xamanismo, trocas "positicas" e "negativas" produzirão um sentido para efeito da análise, mas não, necessariamente, para os atores sociais envolvidos no xamanismo.

${ }^{11}$ Considere como contraste os Aweti do Xingu, que vêem sentido apenas em feitiços entre pessoas geograficamente próximas e em relação (VANZOLINI, 2011, p. 212).

\section{REFERÊNCIAS BIBLIOGRÁFICAS}

ANDRADE, Ugo Maia. O real que não é visto. Xamanismo e relação no baixo Oiapoque. Tese de doutorado em Antropologia Social - PPGAS-USP, 327 p. 2007.

. Memória e diferença: os Tumbalalá e as redes de trocas no submédio São Francisco. São Paulo: Humanitas/FAPESP, 2008. 
. Sobre artefatos-pessoa e produção ritual no baixo Oiapoque - Amapá. $\overline{\text { Revista }}$ de Antropologia. São Paulo, v. 55, n. 2, p. 971-1016, 2012a.

. A Jurema tem dois gaios: história Tumbalalá. In: CARVALHO, Maria Rosário G. de; CARVALHO, Ana Magda de. (orgs.). Índios e caboclos: a história recontada. Salvador: EDUFBA, p. 183-222, 2012b.

. A forma e o espírito: Bancos e Mastros rituais como pessoas invisíveis. In: VIDAL, Lux B.; LEVINHO, José C. e GRUPIONI, Luis D. (orgs.). A presença do invisivel: vida cotidiana e ritual entre os povos indígenas do Oiapoque, Rio de Janeiro: Iepé / Museu do Índio, p. 174-186, 2016.

. Na fronteira: mobilidades xamânicas entre Brasil e Guiana Francesa. Horizontes Antropológicos, Porto Alegre, ano 24, n. 51, p. 203-227, 2018.

ARNAUD, Expedito. O xamanismo entre os índios da região do Uaçá. Boletim do Museu Paraense Emílio Goeldi, nova série, Antropologia, n. 44, p. 1-22, 1970.

. O sobrenatural e a influência cristã entre os índios do rio Uaçá (Oiapoque, Amapá): Palikur, Galibi e Karipuna. In: LANGDON, Esther Jean Matteson (org.). Xamanismo no Brasil: novas perspectivas. Florianópolis: Editora da UFSC, 1996.

BATISTA, Mércia R. Rangel. Laudo Antropológico do Grupo Autodenominado Tumbalalá - Bahia. Rio de Janeiro: dig, 2001.

BOURDIEU, Pierre. O Poder Simbólico. Rio de Janeiro: Bertrand Brasil, 1998[1989].

BUCHILLET, Dominique. Sorcery beliefs, transmission of shamanic knowledge, and therapeutic practice among the Dessana of the Upper Rio Negro region, Brazil. In: WHITEHEAD, Neil L.; WRIGHT, Robin (eds.) In darkness and secrecy. The anthropology of assault sorcery and witchcraft in Amazonia. Durham: Duke University Press, p. 109-131, 2004.

BUTT, Audrey. The shaman's legal role. Revista do Museu Paulista, Nova Série, XVI, p. 151-186, 1966.

CAPIBERIBE, Artionka M. G. Batismo de fogo: os Palikur e o cristianismo. São Paulo: Annablume/FAPESP/NUTI, 2007.

CARNEIRO DA CUNHA, Manuela. Pontos de vista sobre a floresta amazônica: xamanismo e tradução. Mana, v. 4, n. 1, p. 7-22, 1998. 7-22, 1998.

CCPIO - Conselho dos Caciques dos Povos Indígenas do Oiapoque. Protocolo de consulta dos Povos Indígenas do Oiapoque. São Paulo: Iepé, 2019.

DESCOLA, Philippe. Beyond nature and culture. Chicago: The University of Chicago Press, 2013.

DETIENNE, Marcel. Comparar o incomparável. São Paulo: Ideias \& Letras, 2004.

ELIADE, Mircea. El chamanismo y las técnicas arcaicas del éxtasis. Ciudad del México: Fondo de Cultura Económica, 1986.

GALLOIS-CEDI. Povos Indigenas no Brasil: Amapá e Norte do Pará. São Paulo, v. 3, 1983.

GALLOIS, Dominique Tilkin. Introdução. In: Redes de relações nas Guianas. São Paulo: Associação Editorial Humanitas, FAPESP, 2005.

98 HANNERZ, Ulf. The global ecumene as a network of networks. In: KUPER, Adam. (ed.) Conceptualizing Society. New York: Routledge, 1992.

LANGDON, Esther Jean M. Introduction: shamanism and anthropology. In: LANGDON, Esther Jean M.; BAER, Gerhard. Portals of power: shamanism in South America. Albuquerque: University of New Mexico Press, 1-21, 1992. 
LANGDON, Esther Jean M. Introdução: Xamanismo - velhas e novas perspectivas. In:_(org.).Xamanismo no Brasil: novas perspectivas. Florianópolis: Editora da UFSC, 1996.

LIMA, Edilene Coffaci de; CÓRDOBA, Lorena. Apresentação. In:_(orgs.). Os outros dos outros: relações de alteridade na etnologia sul-americana. Curitiba: Ed. UFPR, p. 12-18, 2011.

MALCHER, José. Índios da região do rio Oiapoque. In: RONDON, Cândido Mariano da Silva (org.). Índios do Brasil - das cabeceiras do Rio Xingu, dos Rios Araguaia e Oiapoque (vol. II). Brasília: Senado Federal, p. 245-306, 2019. MÉTRAUX, Alfred. Le shamanisme chez les Indiens de l'Amerique du Sud tropicale - I. Acta Americana, v. 2, n. 3, p. 197-2019, 1944.

NIMUENDAJÚ, Curt. Os índios Palikur e seus vizinhos. Tradução de Thekla Hartmann do original "Die Palikur Indianer und ihre Nachbarn". NHII/USP, mimeo, 1926.

PASSES, Alan. Not alone in the multiverse: borrowing from others, remain Pa'ikwené (Palikur). Comunicação apresentada no colóquio Guiana Ameríndia: etnologia e história. Realização NHII-USP, EREA/CNRS e Museu Emílio Goeldi. Belém, 2006.

RIVIÈRE, Peter. O indivíduo e a sociedade na Guiana. São Paulo: Edusp, 2001.

SAMPAIO-SILVA, Orlando. Tuxá: índios do nordeste. São Paulo: Annablume, 1997.

TASSINARI, Antonella M. I. No bom da festa: o processo de construção cultural das famílias Karipuna do Amapá. São Paulo: Edusp, 2003.

TASSINARI, Antonella M. I. História e parentesco Galibi-Marworno. Comunicação apresentada no colóquio Guiana Ameríndia: etnologia e história. Realização NHII-USP, EREA/CNRS e Museu Emílio Goeldi. Belém, 2006.

VANZOLINI, Marina. O parentesco pervertido: nota sobre a feitiçaria entre os Aweti do Alto Xingu. In: LIMA, Edilene Coffaci de; CÓRDOBA, Lorena (orgs.). Os outros dos outros: relações de alteridade na etnologia sul-americana. Curitiba: Ed. UFPR, p. 211-223, 2011.

VIDAL, Silvia; WHITEHEAD, Neil L. Dark shamans and the shamanic state: sorcery and witchcraft as political process in Guyana and Venezuelan Amazon. In: WHITEHEAD, Neil L.; WRIGHT, Robin (eds.) In darkness and secrecy. The anthropology of assault sorcery and witchcraft in Amazonia. Durham: Duke University Press, pp. 51-81, 2004.

VIDAL, Lux B. Outros viajantes. Revista USP, n. 46, p. 42-51, 2000.

VIDAL, Lux; TASSINARI, Antonela. De cunhados a irmãos: afinidade e consangüinidade Galibi-Marworno. Comunicação apresentada no GT Desenvolvimentos recentes do Americanismo Tropical. XXIII RBA, Gramado, 2002.

VIVEIROS DE CASTRO, Eduardo B. Perspectivismo e multinaturalismo na América indígena. In:_A inconstância da alma selvagem e outros ensaios de antropologia. São Paulo: Cosac \& Naify, p. 347-399, 2002.

VIVEIROS DE CASTRO, Eduardo B. Exchanging perspectives: the transformation of objects into subjects in Amerindian ontologies. Common Knowledge, 10(3), p. 463-484, 2004.

WILBERT, Johannes. The order of dark shamans among the Warao. In: WHITEHEAD, Neil L.; WRIGHT, Robin (eds.) In darkness and secrecy. The anthropology of assault sorcery and witchcraft in Amazonia. Durham: Duke University Press, p. 22-50, 2004.

WRIGHT, Robin. The wicked and the wise men: witches and prophets in the history of the Northwest Amazon. In: WHITEHEAD, Neil L.; WRIGHT, Robin (eds.) In darkness and secrecy. The anthropology of assault sorcery and witchcraft in Amazonia. Durham: Duke University Press, p. 82-108, 2004. 
SUBMETIDO EM: 17/03/2019

APROVADO EM: 15/10/2019 